NASA/TM-2016-219158

\title{
Performance Testing of a High Temperature Linear Alternator for Stirling Convertors
}

Jonathan F. Metscher and Steven M. Geng

Glenn Research Center, Cleveland, Ohio 


\section{NASA STI Program . . . in Profile}

Since its founding, NASA has been dedicated to the advancement of aeronautics and space science. The NASA Scientific and Technical Information (STI) Program plays a key part in helping NASA maintain this important role.

The NASA STI Program operates under the auspices of the Agency Chief Information Officer. It collects, organizes, provides for archiving, and disseminates NASA's STI. The NASA STI Program provides access to the NASA Technical Report Server-Registered (NTRS Reg) and NASA Technical Report ServerPublic (NTRS) thus providing one of the largest collections of aeronautical and space science STI in the world. Results are published in both non-NASA channels and by NASA in the NASA STI Report Series, which includes the following report types:

- TECHNICAL PUBLICATION. Reports of completed research or a major significant phase of research that present the results of NASA programs and include extensive data or theoretical analysis. Includes compilations of significant scientific and technical data and information deemed to be of continuing reference value. NASA counter-part of peer-reviewed formal professional papers, but has less stringent limitations on manuscript length and extent of graphic presentations.

- TECHNICAL MEMORANDUM. Scientific and technical findings that are preliminary or of specialized interest, e.g., "quick-release" reports, working papers, and bibliographies that contain minimal annotation. Does not contain extensive analysis.
- CONTRACTOR REPORT. Scientific and technical findings by NASA-sponsored contractors and grantees.

- CONFERENCE PUBLICATION. Collected papers from scientific and technical conferences, symposia, seminars, or other meetings sponsored or co-sponsored by NASA.

- SPECIAL PUBLICATION. Scientific, technical, or historical information from NASA programs, projects, and missions, often concerned with subjects having substantial public interest.

- TECHNICAL TRANSLATION. Englishlanguage translations of foreign scientific and technical material pertinent to NASA's mission.

For more information about the NASA STI program, see the following:

- Access the NASA STI program home page at http://www.sti.nasa.gov

- E-mail your question to help@sti.nasa.gov

- $\quad$ Fax your question to the NASA STI Information Desk at 757-864-6500

- Telephone the NASA STI Information Desk at 757-864-9658

- Write to:

NASA STI Program

Mail Stop 148

NASA Langley Research Center Hampton, VA 23681-2199 
NASA/TM—2016-219158

\section{Performance Testing of a High Temperature Linear Alternator for Stirling Convertors}

Jonathan F. Metscher and Steven M. Geng

Glenn Research Center, Cleveland, Ohio

Prepared for the

14th International Energy Conversion Engineering Conference (IECEC)

sponsored by AIAA

Salt Lake City, Utah, July 25-27, 2016

National Aeronautics and

Space Administration

Glenn Research Center

Cleveland, Ohio 44135 


\section{Acknowledgments}

This work was funded with the support of the NASA Science Mission Directorate and the Radioisotope Power Systems Program Office. The authors thank YongSu Kim and Gary Wood for their work in determining the epoxy bond thickness needed to bond the magnets and Sunpower, Inc. for building the HTLA. The authors also thank Paul Schmitz for the systems analyses he performed indicating the importance and need for a HTLA.

This report contains preliminary findings, subject to revision as analysis proceeds.

Trade names and trademarks are used in this report for identification only. Their usage does not constitute an official endorsement, either expressed or implied, by the National Aeronautics and Space Administration.

Level of Review: This material has been technically reviewed by technical management.

Available from

NASA STI Program

Mail Stop 148

NASA Langley Research Center

Hampton, VA 23681-2199
National Technical Information Service 5285 Port Royal Road Springfield, VA 22161 703-605-6000

This report is available in electronic form at http://www.sti.nasa.gov/ and http://ntrs.nasa.gov/ 


\title{
Performance Testing of a High Temperature Linear Alternator for Stirling Convertors
}

\author{
Jonathan F. Metscher and Steven M. Geng \\ National Aeronautics and Space Administration \\ Glenn Research Center \\ Cleveland, Ohio 44135
}

\begin{abstract}
The NASA Glenn Research Center has conducted performance testing of a high temperature linear alternator (HTLA) in support of Stirling power convertor development for potential future Radioisotope Power Systems (RPS). The high temperature linear alternator is a modified version of that used in Sunpower's Advanced Stirling Convertor (ASC), and is capable of operation at temperatures up to $200{ }^{\circ} \mathrm{C}$. Increasing the temperature capability of the linear alternator could expand the mission set of future Stirling RPS designs. High temperature Neodymium-Iron-Boron (Nd-Fe-B) magnets were selected for the HTLA application, and were fully characterized and tested prior to use. Higher temperature epoxy for alternator assembly was also selected and tested for thermal stability and strength. A characterization test was performed on the HTLA to measure its performance at various amplitudes, loads, and temperatures. HTLA endurance testing at $200{ }^{\circ} \mathrm{C}$ is currently underway.
\end{abstract}

\section{Nomenclature}

$\begin{array}{ll}\text { ASC } & \text { Advanced Stirling Convertor } \\ \text { ASRG } & \text { Advanced Stirling Radioisotope Generator } \\ \text { ATR } & \text { Alternator Test Rig } \\ B & \text { magnetic induction }(\mathrm{G}) \\ B_{r} & \text { remanent magnetic induction }(\mathrm{G}) \\ \text { DOE } & \text { Department of Energy } \\ \text { FLDT } & \text { Fast Linear Displacement Transducer } \\ \text { GRC } & \text { Glenn Research Center } \\ H & \text { magnetic field strength (kOe) } \\ H_{c i} & \text { intrinsic coercivity (kOe) } \\ \text { HTLA } & \text { High Temperature Linear Alternator } \\ \text { LA } & \text { linear alternator } \\ \text { LMSSC } & \text { Lockheed Martin Space Systems Company } \\ M & \text { magnetization (G) } \\ P_{c} & \text { permeance coefficient } \\ \text { RPS } & \text { Radioisotope Power System } \\ \text { SCTDP } & \text { Stirling Cycle Technology Development Project }\end{array}$




\section{Introduction}

The Thermal Energy Conversion Branch at the NASA Glenn Research Center (GRC) and Sunpower, Inc. have developed a high temperature linear alternator (HTLA) in support of Stirling convertor technology development for potential Radioisotope Power Systems (RPS). The HTLA design is based on the linear alternator (LA) of the Advanced Stirling Convertor (ASC), developed by Sunpower, Inc. under contract to GRC. The ASC was used in the Advanced Stirling Radioisotope Generator (ASRG), developed by Lockheed Martin Space Systems Company (LMSSC) under contract to the Department of Energy. Figure 1 shows a pair of ASCs and a cutaway diagram of the ASRG showing one of the two the ASCs and general purpose heat source (GPHS). Although the ASRG flight development program was canceled and the NASA ASC contract with Sunpower has ended, Stirling research is continuing under the Stirling Cycle Technology Development Project at GRC (Ref. 1).

In support of the ASRG program, the NASA GRC conducted in-house permanent magnet and linear alternator research including finite-element modeling and hardware testing. Magnet characterization and aging tests have been performed on various grades of $\mathrm{Nd}-\mathrm{Fe}-\mathrm{B}$ magnets, including those used in the HTLA, to determine their performance at various temperatures and the stability of their magnetic properties after extended exposure to high temperature and an external demagnetizing field (Ref. 2). Permanent magnet characterization data was used in finite-element models developed using ANSYS Maxwell, an electromagnetic field simulation software, to predict the maximum operating temperature of the ASC LA (Ref. 3). The maximum operating temperature of the ASC LA was determined to be around $130{ }^{\circ} \mathrm{C}$, above which irreversible demagnetization will occur. The HTLA was designed as a potential replacement for the ASC LA and designed to operate at temperatures up to $200{ }^{\circ} \mathrm{C}$.

\section{Need for High Temperature Linear Alternator for Future RPS}

The temperature of the ASC LA permanent magnets is a few degrees higher than the alternator housing (pressure vessel) temperature, so to prevent irreversible demagnetization in the ASRG, Lockheed Martin set the maximum alternator housing temperature specification at $104{ }^{\circ} \mathrm{C}$, providing margin to ensure the magnets are kept at a safe temperature. The ASRG was designed for an operating sink temperature between 4 and $250 \mathrm{~K}$, depending on the environment. At a $250 \mathrm{~K}$ sink temperature for the ASRG, thermal models predict the ASC alternator housing temperature to be approximately $84{ }^{\circ} \mathrm{C}$, below the design specification of $104{ }^{\circ} \mathrm{C}$. There are, however, several operating environments where the ASRG would experience a sink temperature greater than $250 \mathrm{~K}$. For example, IR/albedo energy radiated from the lunar surface as well as contamination of the ASRG radiator from lunar soil makes the Moon a challenging operating environment. Lunar soil has low thermal conductivity that may give an insulating effect where it contaminates the ASRG radiator. The increased solar absorptivity and reduced thermal emissivity of the radiator, while operating on the lunar surface, could lead to a sink temperature as high as $340 \mathrm{~K}$ (Fig. 2) (Ref. 4). A $340 \mathrm{~K}$ sink temperature would result in alternator housing temperatures around $120^{\circ} \mathrm{C}$, exceeding the $104^{\circ} \mathrm{C}$ design specification and approaching maximum magnet temperature.

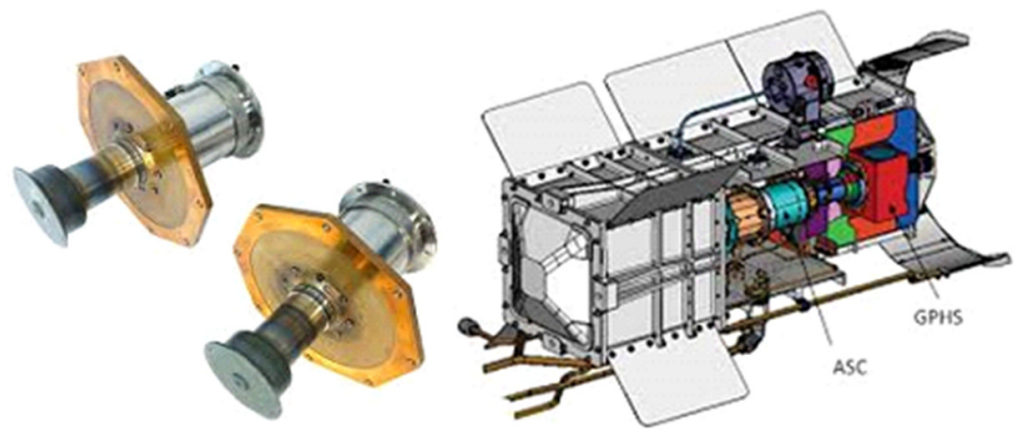

Figure 1.-Pair of ASCs and ASRG cutaway diagram. 


\section{Horizontal and Vertical Radiator Sink Temperatures as a Function of Hours after Dawn Located at the Equator}

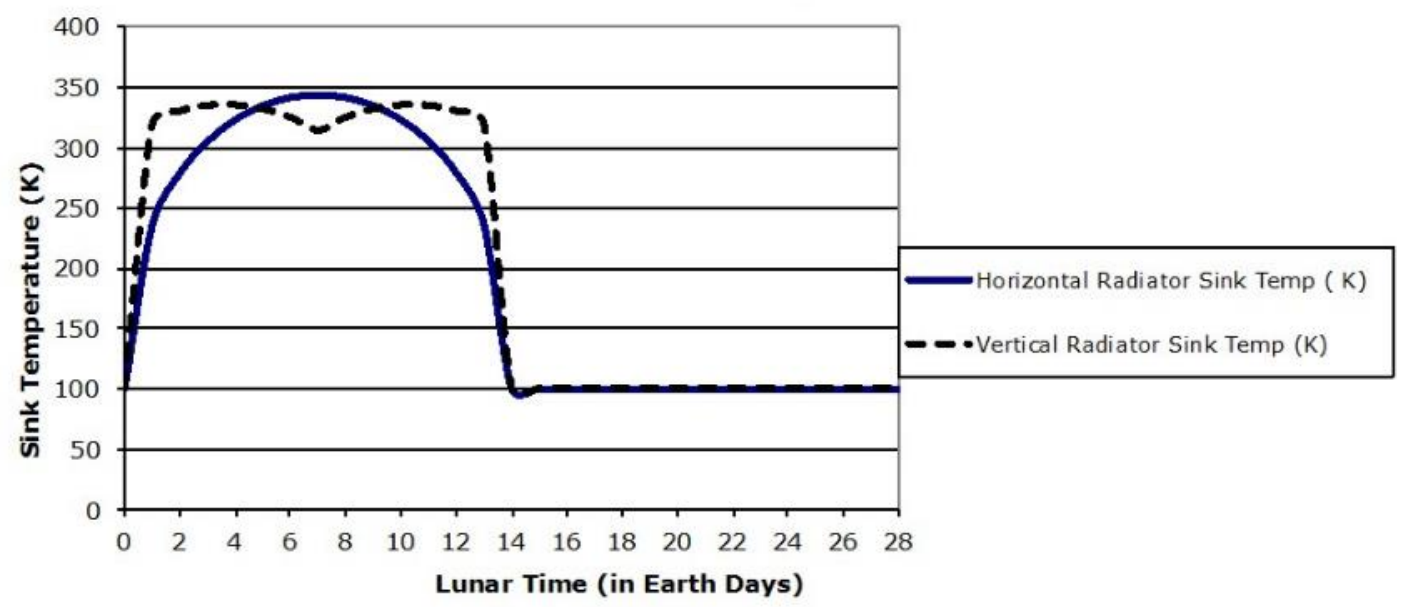

Figure 2.-Plot of lunar sink temperature (Ref. 4).

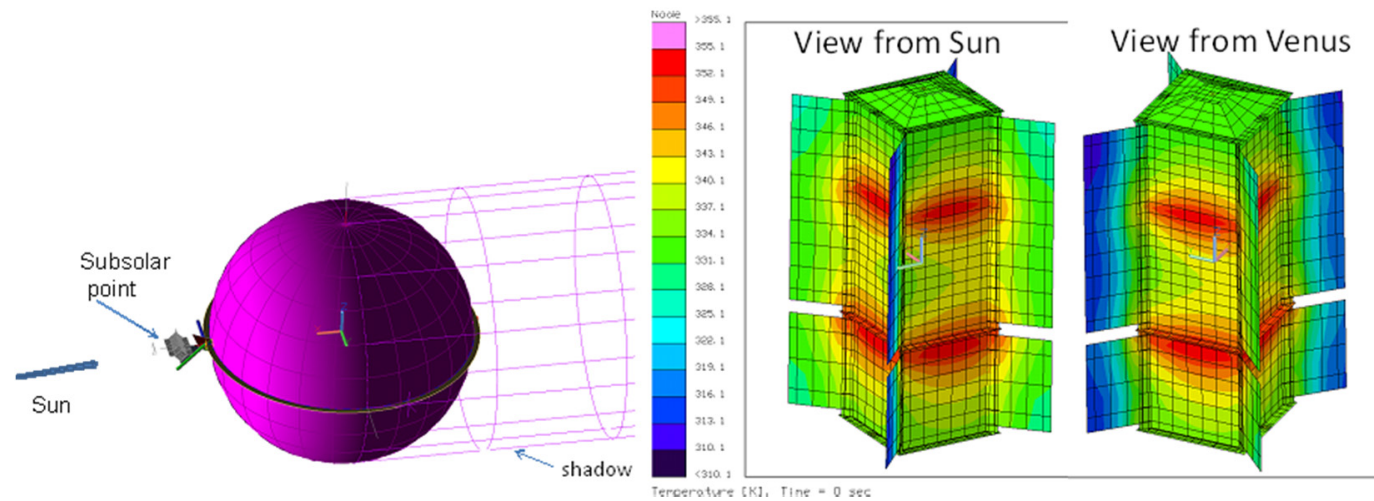

Figure 3.-Depiction of spacecraft position during Venus swing-by and ASRG thermal analysis (Ref. 6).

A Mars surface mission potentially presents two thermal scenarios that would require a higher alternator operating temperature. First, missions to regions of Mars designated under planetary protection provisions, where water ice is expected within $5 \mathrm{~m}$ of the surface, are required to undergo strict sterilization procedures to eliminate microbes to prevent possible contamination of the Martian environment. One method of sterilization is to use Dry Heat Microbial Reduction (DHMR) in which spacecraft components would be heated to 104 to $125^{\circ} \mathrm{C}$ (Ref. 5). A sink temperature of $104{ }^{\circ} \mathrm{C}$ for the ASRG would cause the alternator housing temperature to exceed $150{ }^{\circ} \mathrm{C}$ and demagnetize the LA, if the DHMR was performed when the generator was fueled. Second, the Mars Curiosity rover experiences sink temperatures up to $277 \mathrm{~K}$, but the ASRG sink temperature limit for Mars is $240 \mathrm{~K}$. The alternator housing temperature would be below its maximum temperature at a sink temperature of $277 \mathrm{~K}$, however it would be operating above this design specification and within the margin of safety.

Similarly, a mission that requires a swing-by of Venus for a gravity assist maneuver could also experience increased sink temperatures that exceed the design specifications. During a swing-by, the spacecraft could come as close as $300 \mathrm{~km}$ from the surface and experience reflected solar radiation and IR radiation from Venus, in addition to direct solar radiation. Thermal models (Fig. 3) of the ASRG during a Venus flyby indicates the ASC alternator housing possibly reaching $110^{\circ} \mathrm{C}$. Although this is less than the maximum magnet temperature of $130{ }^{\circ} \mathrm{C}$, it is above the $104{ }^{\circ} \mathrm{C}$ design limit and is a risk, especially considering certain assumptions are required for the simulation (Ref. 6). 
Increasing the LA maximum operating temperature beyond that of the current ASC LA would expand the potential mission set for any future Stirling RPS program to include the above examples. Additionally, it would expand the design space of a future RPS by allowing optimization of the generator housing and radiator panels to achieve higher specific power. To increase the maximum operating temperature of the ASC LA requires magnets with a higher $H_{c}$ and for the load-line to operating the reversible region of the $\mathrm{B}-\mathrm{H}$ curve. This requires demagnetization test data to accurately define the B-H curves of the permanent magnet. The organics used to bond the magnets to the piston assembly of the ASC must also be capable of long duration operation at high temperatures and testing to determine proper curing temperatures and procedures to ensure a strong bond. The HTLA presented in this paper is modified from the ASC LA and uses high temperature $\mathrm{Nd}-\mathrm{Fe}-\mathrm{B}$ magnets and high temperature organics tested at GRC, enabling operation up to $200{ }^{\circ} \mathrm{C}$ before risking demagnetization. A review of the work done to develop the HTLA will be presented in the following section and followed by the HTLA test setup and review of test results.

\section{Increasing Linear Alternator Temperature Limits}

Permanent magnets experience irreversible demagnetization if their temperature exceeds the maximum operating temperature, which is determined by the magnet material properties and the loadline, or permeance coefficient $\left(P_{c}\right)$, of the magnetic circuit. As the temperature of a permanent magnet increases, its resistance to demagnetization, or intrinsic coercive force $\left(H_{c i}\right)$, decreases as shown by the $\mathrm{M}-\mathrm{H}$ curves in Figure 4. If the temperature of the permanent magnet increases such that the load-line is below the "knee" of the M-H curve, or if an adverse magnetic field of magnitude near $H_{c i}$ is applied, then irreversible demagnetization will occur.

To increase the maximum operating temperature of the ASC LA requires selecting magnets that have a higher $H_{c i}$. A survey of available magnet grades was conducted and a selection made that provided increased $H_{c i}$ while keeping a similar remanent magnetic induction $\left(B_{r}\right)$ to that of the ASC LA in order to maintain similar alternator performance. NEOMAX N32EZ magnets were selected for the HTLA based on these criteria, enabling operation at temperatures up to $200^{\circ} \mathrm{C}$. Additionally, Henkel Hysol EA9394C-2 was selected as a high temperature epoxy for alternator assembly and is necessary to increase the temperature capability of the alternator.

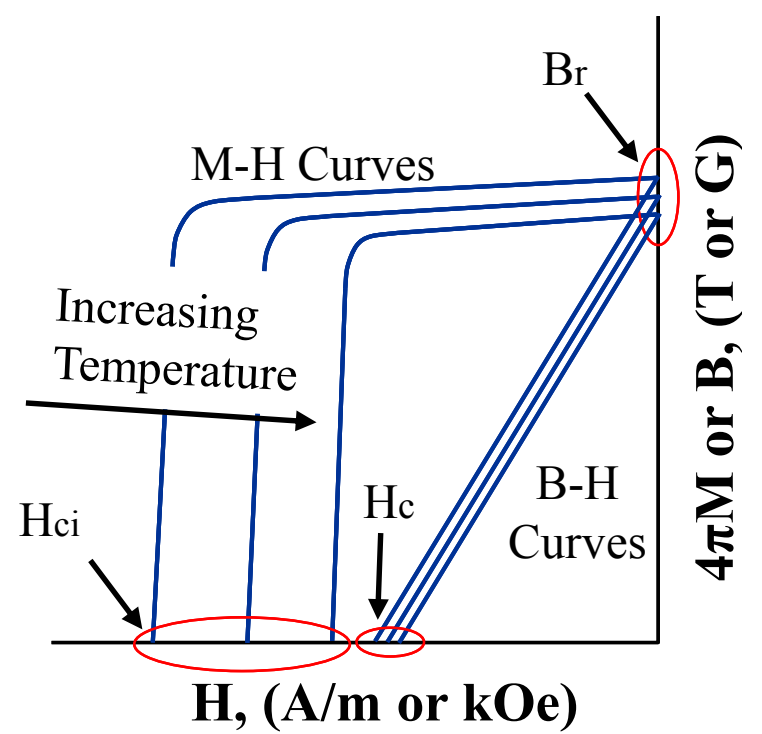

Figure 4.-Sample demagnetization curve. 


\section{Permanent Magnet Characterization and Aging Testing}

The N32EZ magnet grade selected for the HTLA underwent magnet characterization testing as well as short and long term aging tests at GRC to understand the magnet's performance at elevated temperature and stability of magnetic properties over time. Testing was conducted on $1 \mathrm{~cm}^{3}$ magnet samples that were initially magnetized using a capacitor-discharge pulse magnetizer at GRC. The sample magnets were then characterized using an electromagnet (Fig. 5) and a pair of sensing coils inside the test paddle. Magnet samples were placed in the test paddle that encircles them with a sensing coil to measure the flux density, from which the magnetization $(M)$ was derived. A second sensing coil in the paddle was used to directly measure the magnetic field strength $(H)$. The paddle, with magnet sample, was placed between the pole pieces of the electromagnet and held by the temperature control fixture which is capable of controlling the temperature of the magnet sample up to $300{ }^{\circ} \mathrm{C}\left( \pm 3{ }^{\circ} \mathrm{C}\right)$. The electromagnet applies a demagnetizing field to the magnet samples held at various temperatures, and measurements from the two paddle sensing coils are recorded. The data is used to plot the M-H curves of the magnet sample, similar to those shown in Figure 4.

After initial characterization, magnet samples were placed into a magnet aging fixture for aging testing. The magnet aging fixture (Fig. 6) controls the temperature of 10 magnet samples in a helium environment. Figure 7 shows the magnet aging fixture installed in the electromagnet used for aging tests. In the magnet aging test, magnet samples were held at an operating point for an extended duration that brought them close to the knee of the $\mathrm{M}-\mathrm{H}$ curve without causing demagnetization. After the test duration, the magnet samples were characterized again to determine if there was a decrease in $B_{r}$ or $H_{c i}$ of the magnet. For the short term aging test, the temperature of the N32EZ magnet samples were held at a temperature of $180^{\circ} \mathrm{C}$ with a demagnetizing field of $12 \mathrm{kOe}$ for $200 \mathrm{hr}$. The short-term test operating point was at increased severity compared to long term aging tests in order to quickly screen out magnet types that would be unsuitable for long-term missions in space. The short-term test of the N32EZ magnets showed a change in $B_{r}$ and $H_{c i}$ of less than 1 percent, which is within the uncertainty range of the measurements. N32EZ magnet samples then underwent long-term aging testing in which the magnets were held at $160{ }^{\circ} \mathrm{C}$ and $14 \mathrm{kOe}$ demagnetizing field for $2000,6000,12000,18000$, and $24000 \mathrm{hr}$ with 2 of the 10 magnet samples removed and characterized at each duration point. The long-term aging test magnet samples experienced a change in $B_{r}$ and $H_{c i}$ around 1 percent.

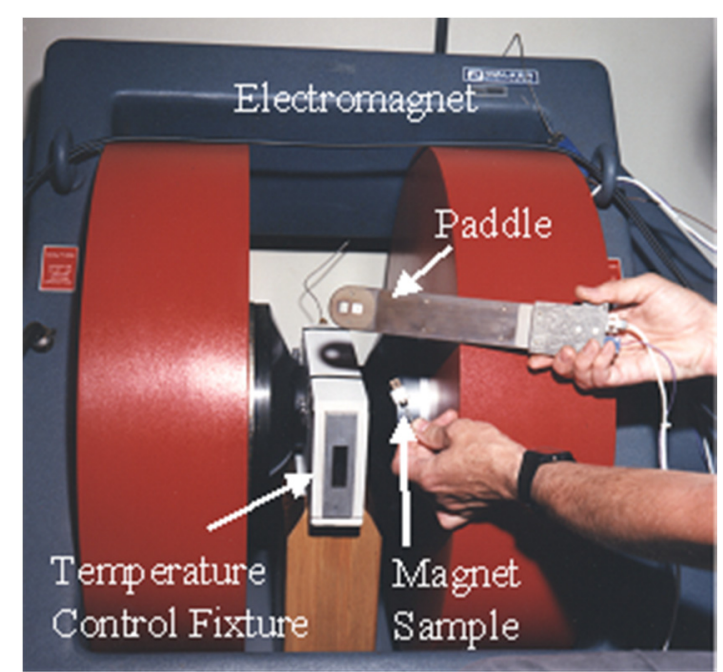

Figure 5.-Electromagnet, temperature control fixture, and magnet characterization paddle. 


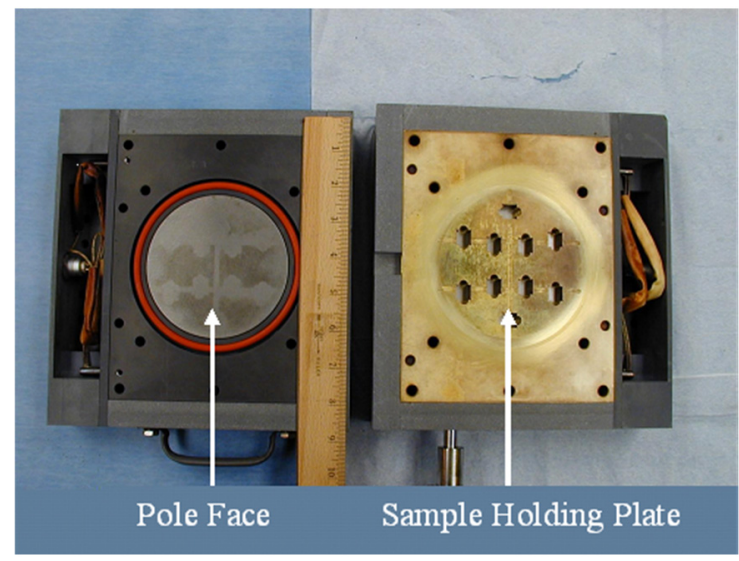

Figure 6.--Separated magnet aging fixture.

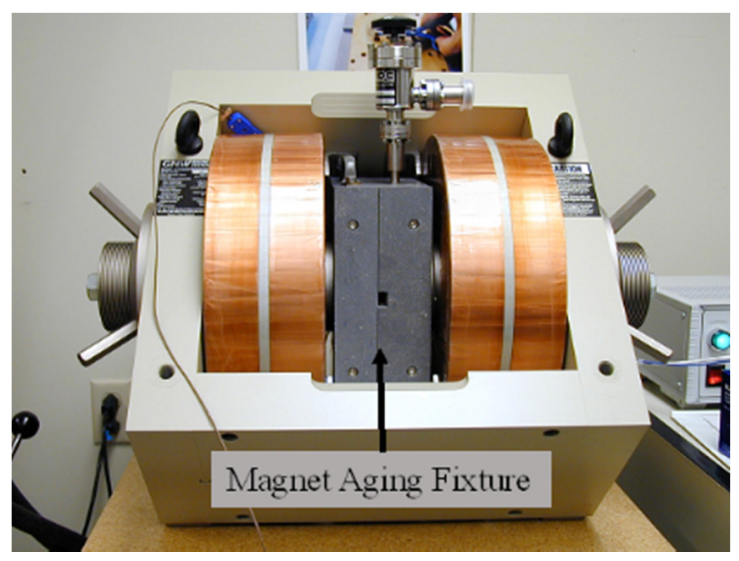

Figure 7.-Magnet aging fixture installed in electromagnet.

\section{High Temperature Hysol Bonding of the Magnets}

Increasing the temperature limits of the LA also required an epoxy able to hold the magnets on the alternator magnet can. Two commercial candidates, Henkel Hysol EA394C-2 epoxy paste and 3M AF131-2 epoxy adhesive, were selected for testing and were evaluated based on short-term thermal stability, bond integrity, outgassing potential, and processability. The Henkel Hysol epoxy was selected for the HTLA after the initial evaluation. Testing continued on both epoxy candidates to evaluate longterm thermal stability, after which the Hysol was recommended for continued use due to its more stable bonding properties and longer-term thermal stability (Ref. 7).

Selecting an epoxy, however, is not the only challenge in bonding magnets for a high temperature application. It was discovered that the N32EZ magnets would de-bond from the magnet can below $200{ }^{\circ} \mathrm{C}$. Nd-Fe-B magnets have a negative thermal coefficient of expansion perpendicular to the magnetic field direction, causing the bonded magnet surface to shrink and pull away from the titanium magnet can as temperature increases. Analysis showed that increasing the bond thickness would solve this problem. The magnet can was rebuilt with a thicker epoxy bond controlled by using Zirconium oxide microspheres mixed with the epoxy.

\section{Support Hardware for Testing the HTLA}

\section{Alternator Test Rig}

The HTLA was tested at GRC using the alternator test rig (ATR). The HTLA is coupled to a drive motor through a flex rod and Kistler load cell. The load cell was used to measure the dynamic force on the alternator, while the mover amplitude was measured using a fast linear displacement transducer (FLDT) mounted to the drive motor. The HTLA and drive motor assembly was enclosed in a containment vessel that was pressurized to $10 \mathrm{psig}$ of helium to reduce degradation of the heated test article. The containment vessel was secured to a large steel block sitting on springs to reduce vibrations of the ATR. Figure 8 shows the coupled HTLA and drive motor secured to the steel mass with the containment vessel opened.

The HTLA was heated by electric heater bands along the inner and outer stator. Each heater band was controlled independently by a DC power supply to achieve the desired alternator temperature. The HTLA was wrapped with Cotronics ceramic paper for insulation and topped with a foam insulation cap. A series of thermocouples was used to measure temperature around the inner and outer stators as well near the alternator mounting plate. 


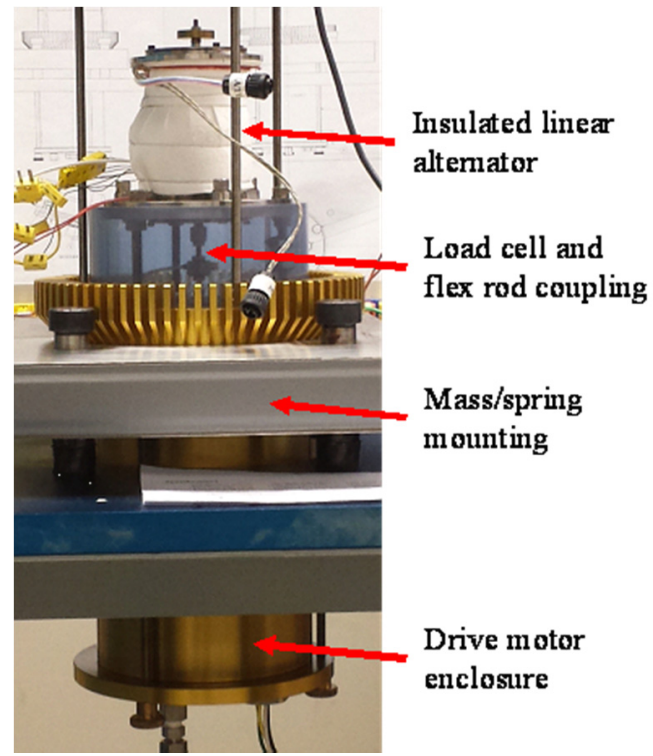

Figure 8.-HTLA coupled to the drive motor.

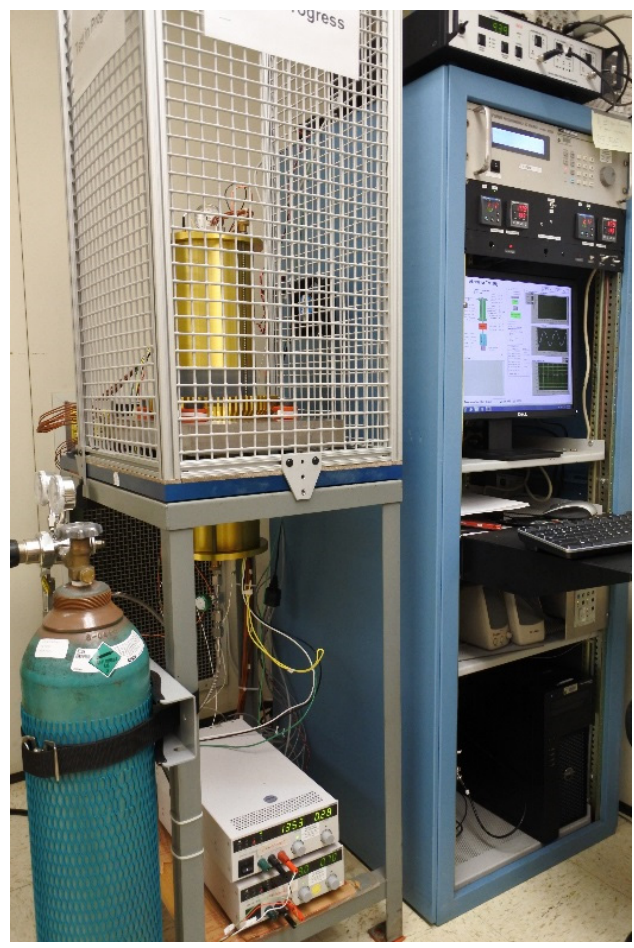

Figure 9.-Alternator test rig (ATR).

The drive motor was powered by a Chroma AC power source operating at $102 \mathrm{~Hz}$ (the design frequency of the HTLA). Electric output of the HTLA was measured with a Yokogawa power meter and connected to a resistive load via a capacitor bank to correct the power factor. Data measured from the power meter, load cell, FLDT, and thermocouples were recorded by a LabVIEW (National Instruments) data acquisition system which then calculated other parameters such as line loss and alternator efficiency. The assembled ATR and test rack is shown in Figure 9.

\section{Test Plan}

The performance of the HTLA changes with the operating conditions such as piston amplitude, alternator resistive load, and temperature. Increasing alternator mover amplitude increases the rate of change of the magnetic field and therefore increases the voltage. Increasing the alternator resistive load reduces the current, lowering $\mathrm{I}^{2} \mathrm{R}$ losses and increasing efficiency, but also lowers output power. A characterization test was performed to better understand these relationships and the performance of the HTLA.

The characterization test plan varied the alternator temperature, mover amplitude, and resistive load to create a performance map of the alternator. The HTLA was operated at 23, 50,100, 150, 180, and $200{ }^{\circ} \mathrm{C}$ using the electric heater bands. At each temperature the LA was tested at 2.5, 3.0, 3.5, 4.0, and $4.5 \mathrm{~mm}$ mover amplitude with the electric load set at $0.5,1.0,1.5,2.0$, and $2.5 \Omega$.

After successful completion of the HTLA performance map, the ATR was then configured to enable $24 \mathrm{hr}$ unattended operation for a 5,000 hr endurance test. The HTLA heater bands were controlled using PIDs and temperature limit controllers. A failure protection circuit was connected to the FLDT to detect any over-strokes, and data was set to be collected hourly by the LabVIEW system. During the endurance test, the HTLA was operated at $200{ }^{\circ} \mathrm{C}$, with a mover amplitude of $4.3 \mathrm{~mm}$ and $0.5 \Omega$ resistive load. 


\section{Test Results and Analysis of the HTLA}

\section{Performance Map of the HTLA}

The planned characterization test consisted of 150 operating points, of which 149 were completed. The final operating point at $200{ }^{\circ} \mathrm{C}$, with $0.5 \Omega$ load and $4.5 \mathrm{~mm}$ amplitude, was omitted to avoid possible demagnetization by exceeding the current limit at that temperature. It is important to recognize that the current limit of the alternator varies with temperature. As temperature increases, the magnet's resistance to demagnetization decreases; and as the current flow through the alternator winding increases, the demagnetization field acting on the magnets increases. Figure 10 shows the power output of the HTLA with increasing temperature at varied resistive loads, while operating at $4.5 \mathrm{~mm}$ amplitude.

Power output decreases with increasing temperature due to a decrease in magnet strength. The reduced magnetic flux from the magnets reduces the rate of change of flux through the alternator coil at a given amplitude, reducing voltage and current. As temperature is increased, mover amplitude also increases as the mechanical load decreases. Drive motor power was decreased in order to maintain mover amplitude, reducing power output. Power output with increasing amplitude is shown in Figure 11 at two temperature points for each resistive load tested.

As temperature increases, the efficiency of the HTLA decreases as shown in Figure 12. Although alternator coil resistance increases with temperature, current decreases from the reduced voltage generated, keeping $\mathrm{I}^{2} \mathrm{R}$ losses nearly constant. The losses are likely due to decreased magnet performance at elevated temperatures, as well as changes in the stiffness of the springs holding the magnet can mounted to the alternator shaft.

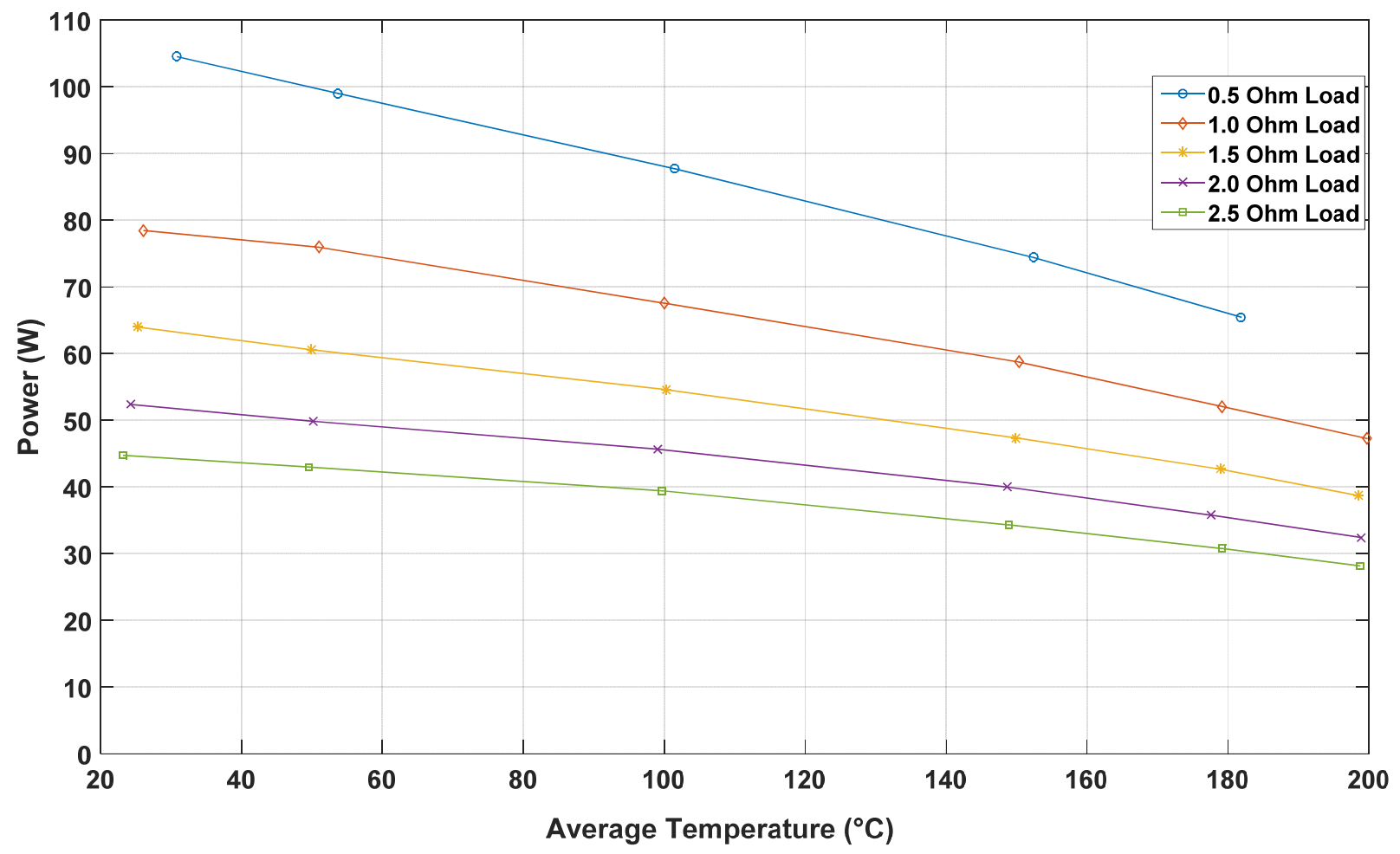

Figure 10.-Power vs. temperature at $4.5 \mathrm{~mm}$ amplitude for each load tested. 


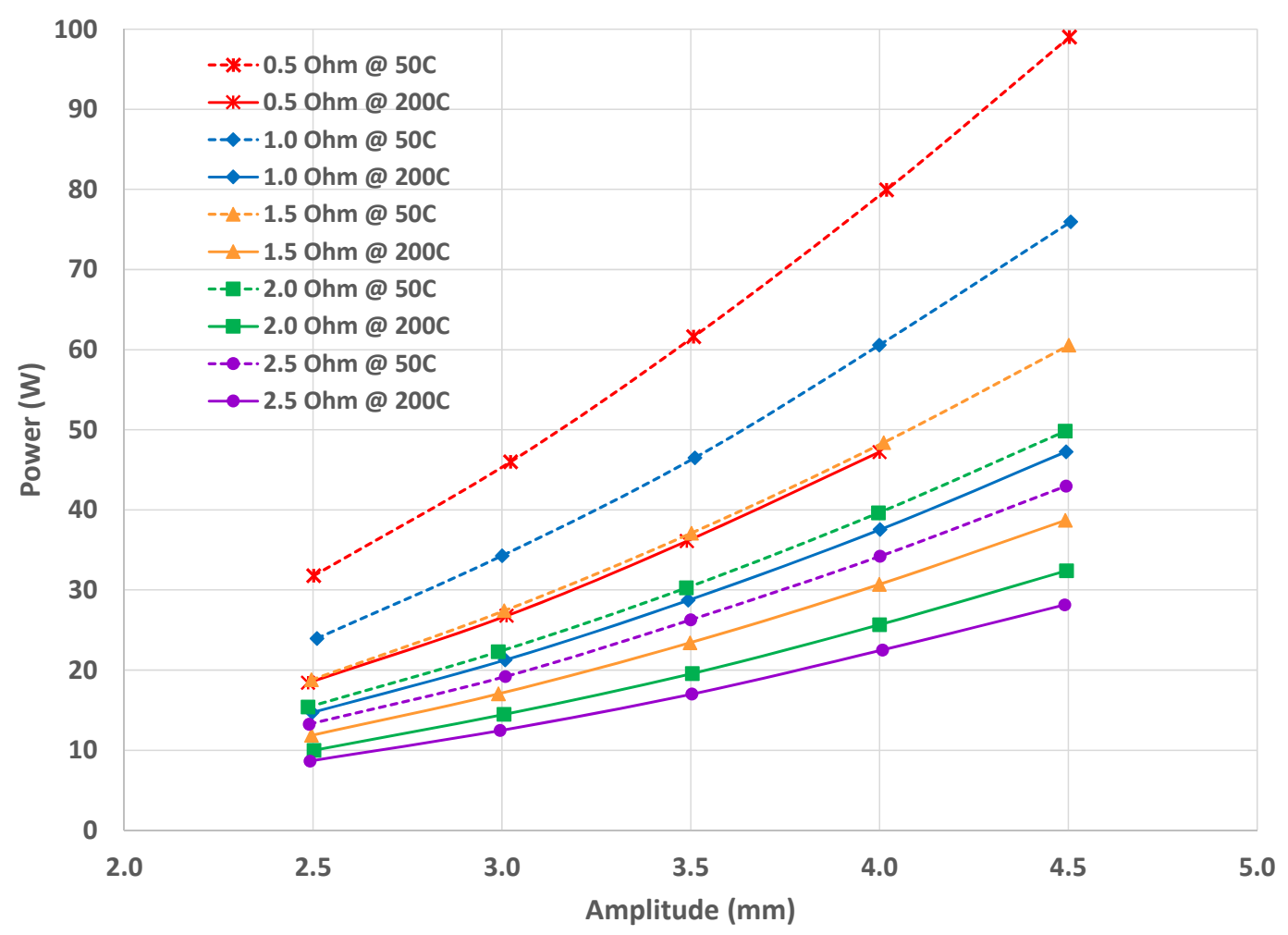

Figure 11.-Power vs. amplitude at 50 and $200{ }^{\circ} \mathrm{C}$ for each load tested.

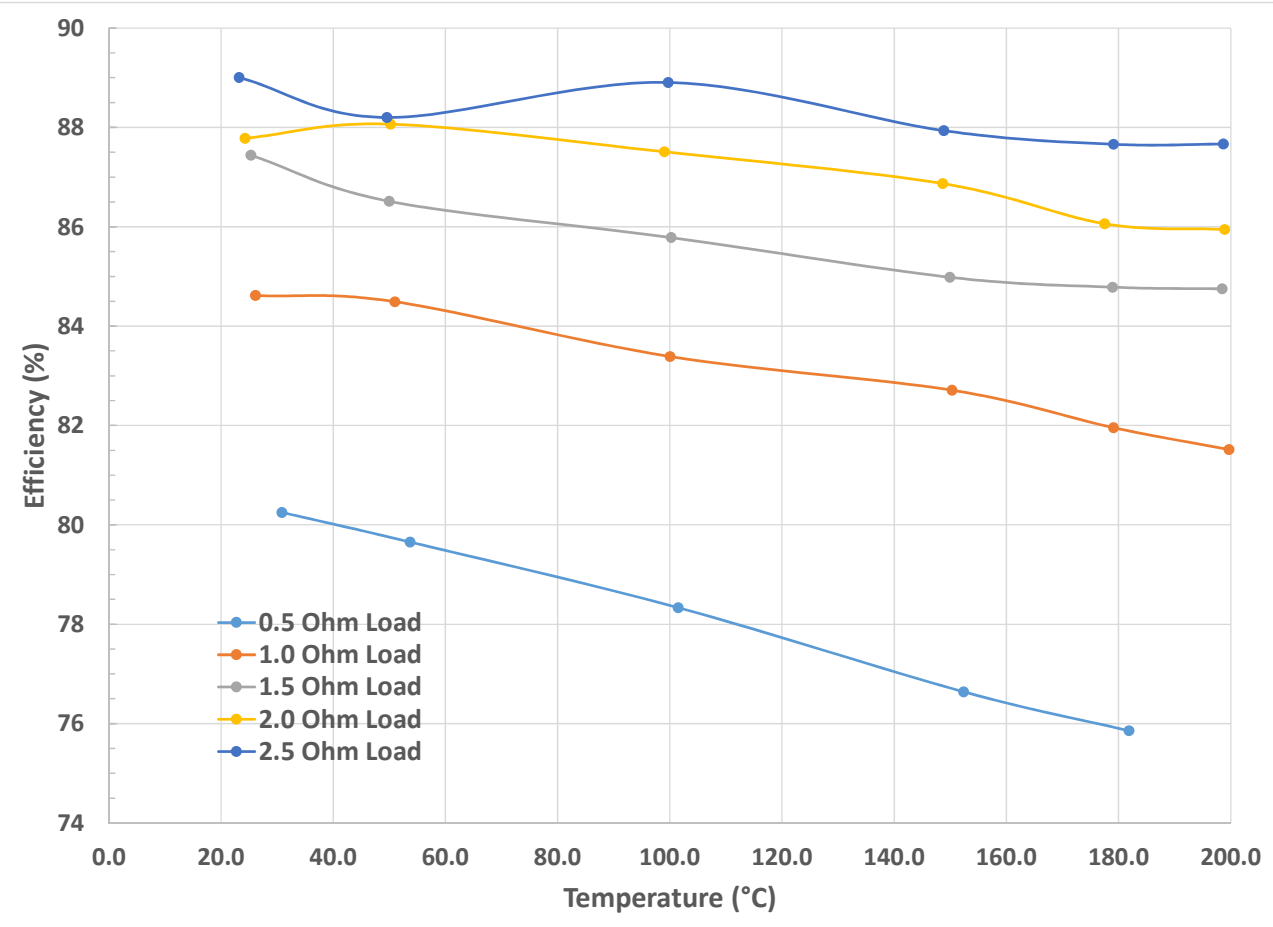

Figure 12.-Efficiency vs. temperature at $4.5 \mathrm{~mm}$ amplitude for each load tested. 


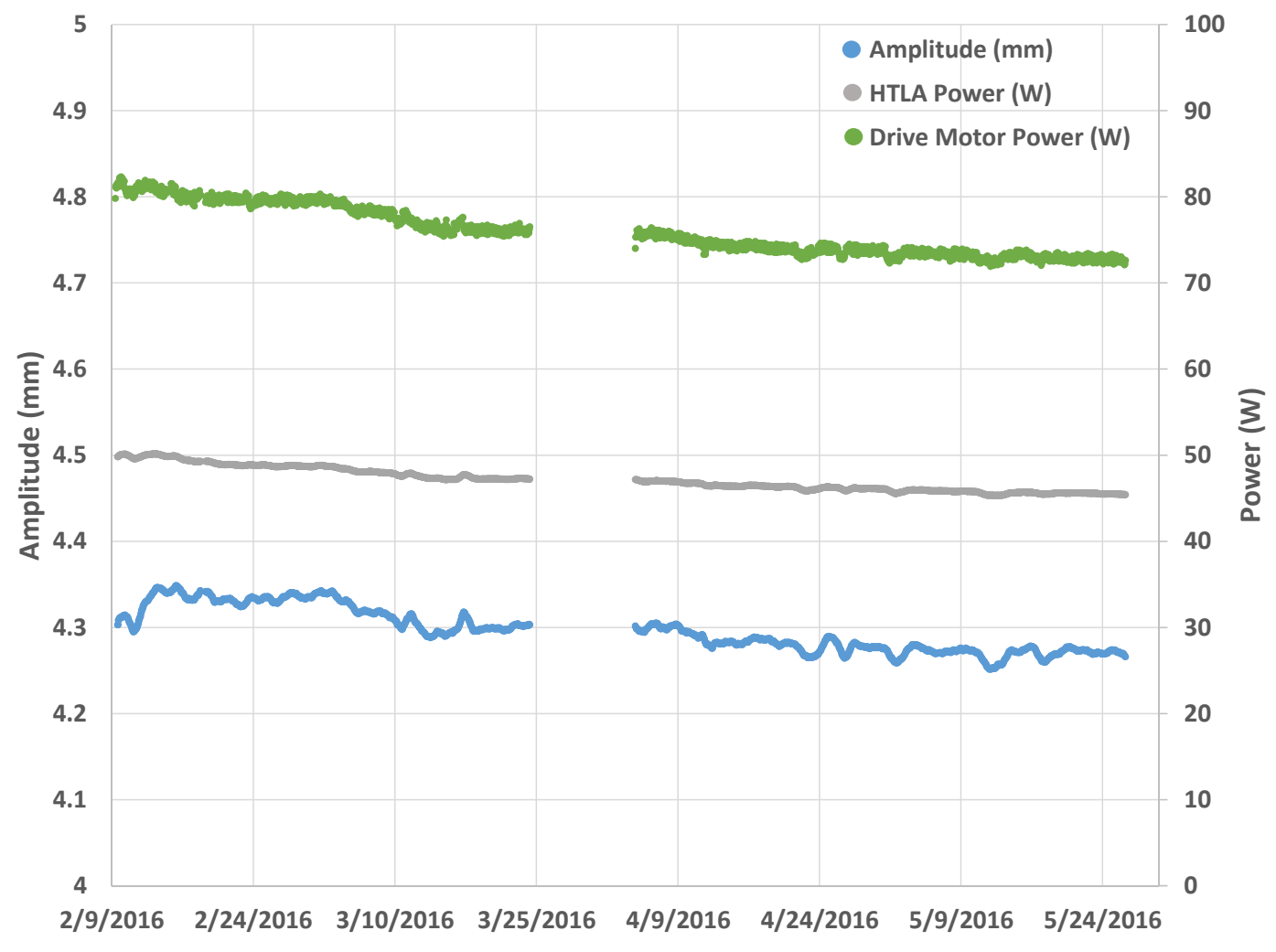

Figure 13.-Endurance test performance plot.

\section{Performance During High Temperature Extended Operation}

After the characterization test was completed, the HTLA began extended operation at $200{ }^{\circ} \mathrm{C}$ to determine if there is long-term degradation of the alternator at high temperature. Testing is being conducted with a $0.5 \Omega$ resistive load and $4.3 \mathrm{~mm}$ mover amplitude, which is the highest safe amplitude that can be achieved in this operating condition without risking demagnetization due to the alternator current. As of the time of this writing, the HTLA has completed over $3000 \mathrm{hr}$ of operation. Figure 13 shows a moving average plot of the HTLA performance during extended operation. There appears to be a slight decrease in power and amplitude over time, but the cause is not clear from the data. Further analysis will be conducted when the test is completed at $5000 \mathrm{hr}$ of operation.

\section{Conclusion}

Performance testing shows the HTLA is capable of operating at temperatures up to $200{ }^{\circ} \mathrm{C}$ without irreversible demagnetization or de-bonding problems. Endurance testing of the HTLA at the time of this writing is over $2400 \mathrm{hr}$ and although there appears to be some change in performance, it is not yet clear if it is a sign of degradation. Further analysis and inspection of the HTLA is needed after endurance testing is completed, and changes to the design may be necessary for extended $200{ }^{\circ} \mathrm{C}$ operation. However, use of the HTLA technology would expand the temperature range of an RPS utilizing Stirling energy conversion, expanding the potential mission set to include Mars and lunar surface missions, Venus swingby, or possibly enable the use of dry heat sterilization procedures while operating. Future testing of the HTLA may include testing the effects of thermal cycling as well as modeling and analysis to understand performance losses and improve the design. 


\section{References}

1. Wilson, S.D., Schifer, N.A., et al., "Overview of Stirling Technology Research at NASA Glenn Research Center," Proceedings of the $13^{\text {th }}$ International Energy Conversion Engineering Conference (IECEC 2015), American Institute for Aeronautics and Astronautics, Orlando, FL, 2015.

2. Geng, S.M., Niedra, J.M., and Schwarze, G.E., "Overview of NASA Magnet and Linear Alternator Research Efforts," Proceedings of Space Technology and Applications International Forum, Albuquerque, NM, 2005, pp. 666-673, NASA/TM-2005-213411.

3. Geng, S.M., Niedra, J.M., and Schwarze, G.E., "Demagnetization Tests Performed on a Linear Alternator for a Stirling Power Convertor," in Proceedings of the $9^{\text {th }}$ International Energy Conversion Engineering Conference (IECEC 2011) American Institute for Aeronautics and Astronautics, 2011.

4. Schmitz, P.C., Penswick, B.L., Shaltens, R.K., "Stirling Isotope Power System for Stationary and Mobile Lunar Applications," in Proceedings of the $4^{\text {th }}$ International Energy Conversion Engineering Conference (IECEC 2006) American Institute for Aeronautics and Astronautics, 2006.

5. "Planetary Protection Provisions for Robotic Extraterrestrial Missions," NASA Science Mission Directorate, NPR-8020.12D, http://nodis3.gsfc.nasa.gov/

6. Wang, X.Y., Fabanich, W.A., Schmitz, P.C., "Thermal Model Prediction of Advanced Stirling Radioisotope Generator Performance," in Proceedings of the $12^{\text {th }}$ International Energy Conversion Engineering Conference (IECEC 2014) American Institute for Aeronautics and Astronautics, 2014.

7. Shin, Euy-Sik E., "Evaluation and Validation of Organic Materials for Advanced Stirling Convertors (ASCs): Overview," in Proceedings of the $13^{\text {th }}$ International Energy Conversion Engineering Conference (IECEC 2015) American Institute for Aeronautics and Astronautics, 2015. 


